\title{
Letter to the editor 'Augmented compression in exchange nailing for femoral and tibia non-unions accelerates time to radiographic union'
}

\author{
Metin Uzun ${ }^{1}$ (D)
}

Received: 1 July 2021 / Accepted: 11 July 2021 / Published online: 23 July 2021

( ) The Author(s), under exclusive licence to Springer-Verlag France SAS, part of Springer Nature 2021

\section{Dear Editor,}

I read the 'Augmented compression in exchange nailing for femoral and tibia non-unions accelerates time to radiographic union' by Weil. They stated augmented compression in exchange nailing for non-union [1]. Honestly, the objective and results of the study are noteworthy and we have some questions for author:

Weil pointed that; It's important to distinguish between augmented compression of the nail construct from loading of the non-union using the dynamic locking holes and the theory behind dynamic locking of the nail is that the fracture/non-union is compressed on cyclical loading. The author, with patients with a mean age of 31 who received additional compressions, compared the results of patients with a mean age of 55.5 years who did not receive additional compressions. Although augmented compressions give better results in more sedentary and elderly patients according to the author's hypothesis and results; author applied augmented compression to a group of young patients with a mean age of 31 years old. It should be clarified why augmented compression is applied to the young patient group instead of the elderly group.
We appreciate the authors' comments on these concerns.

Funding No funding was received from anywhere.

\section{Declarations}

Conflict of interest Author Metin Uzun declares that he has no conflict of interest.

Human and animal rights This article does not contain any studies with human participants or animals performed by any of the authors.

\section{Reference}

1. Weil S, Fontalis A, Guessoum M, Trompeteer A (2021) Augmented compression in exchange nailing for femoral and tibial non-unions accelerates time to radiographic union. Eur J Orthop Surg Traumatol 31:931-936

Publisher's Note Springer Nature remains neutral with regard to jurisdictional claims in published maps and institutional affiliations.

Metin Uzun

drmetinuzun@gmail.com

1 Department of Orthopaedics and Traumatology, Acibadem University, Acibadem Maslak Hospital, 34457 Maslak, İstanbul, Turkey 